\title{
Quantitative Evaluation of Radix Astragali through the Simultaneous Determination of Bioactive Isoflavonoids and Saponins by HPLC/UV and LC-ESI-MS/MS
}

\author{
Jin Hee Kim, ${ }^{a}$ So-Young Park, ${ }^{\dagger a}$ Hyun Kyun Lim, Ah Yeon Park, Ju Sun Kim, \\ Sam Sik Kang, ${ }^{\ddagger}$ Jeong-Rok Youm, and Sang Beom Han \\ Department of Pharmaceutical Analysis, College of Pharmacy, Chung-Ang Eniversity, Seoul 156-756, Korea \\ "E-mail: hansbacau ackr \\ -Enwironmental Toxico-Genomic \& Proteomic Center, College of Uledicine, Korea Liniversity, Seoul 136-701, Korea \\ ${ }^{ \pm}$Natural Products Research Institute, College of Pharmacn, Seoul Kational University, Seoul 110-460, Korea \\ Received March 31, 2007
}

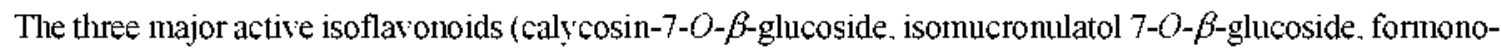
netin) and two main saponins (astragaloside I. astragaloside IV) in an extract of Radix Astragali were determined using rapid. sensitive. reliable HPLC/UV and LC-ESI-MS/MS methods. The separation conditions employed for HPLC $U V$ were optimized using a phenyl-hexyl column $(4.6 \times 150 \mathrm{~mm} .5 \mu \mathrm{mm})$ with the gradient elution of acetonitrile and water as the mobile phase at a flow rate of $1.0 \mathrm{~mL} / \mathrm{min}$ and a detection wavelength of $230 \mathrm{~nm}$. The specificity of the peaks was determined using a triple quadnupole tandem mass spectrometer equipped with an electrospray ionization (ESI) source that was operated in multiple reaction monitoring (MRM) in the positive mode. These methods were fully validated with respect to the linearity, accuracy: precision. recovery and robustness. The HPLC/UV method was applied successfully to the quantification of three major isoflavonoids in the extract of Radix Astragali. The results indicate that the established HPLCJVV and LC-ESI-MS/MS methods are suitable for the quantitative analysis and quality control of multi-components in Radix Astragali.
\end{abstract}

Key Words : Radix, HPLC/UV. LC-ESI-MS/MS, Isoflavonoids. Saponins

\section{Introduction}

Radix Astragali is the dried root of Astragahis membranaceous (Fisch.) Bge. and Astragahis membranaceous (Fisch.) Bge. var. mongolicus (Bge.) Hsiao (Leguninosae). This plant has been used widely in traditional Chinese medicine to tonify' the "Qi" (vital energy) and is prescribed to treat symptoms such as fatigue. lack of appetite. frequent colds. spontaneous sweating and shortness of breath. 'Pharmacological studies have revealed it to have antiviral." hepatoprotective. $^{3}$ antioxidant ${ }^{+}$cardiovascular protective ${ }^{5}$ and immunostimulant activity. ${ }^{6}$ In addition. Radix Astragali has been reported to increase the resistance to the immunosuppressive effects of chemotherapy: ${ }^{7}$ Isoflavonoids triterpene saponins and polysaccharides are the bioactive constituents most often associated with the biological activity' of Radix Astragali. ${ }^{8}$ Among these. isoflavonoids have been chosen as marker compounds for quality evaluations using HPLC/UV ${ }^{\text {y.jo }}$ due to the existence of chromophores for UV detection. or by LC-MS ${ }^{11.12}$ On the other hand. triterpene saponins. such as astragaloside IV in Radix Astragali. have been used for quality control in Chinese Pharmacopoeia. ${ }^{13}$ Several analytical methods have been developed for the determination of saponins in Radix Astragali. However due to the lack of chromophores. most of these have been performed using thin-layer chromatography (TLC) ${ }^{1+}$ high performance liquid chromatography and evaporative light

\footnotetext{
These two authors contributed equally to this work.
}

scattering detection (HPLC-ELSD) ${ }^{15.16 i}$ precolunun derivatization high performance liquid clromatography ${ }^{17}$ and LCMS with solid phase extraction (SPE) ${ }^{1 /}$ Recently, the simultaneous determination of six isoflavonoids and four saponins of Radix Astragali by HPLC-DAD-ELSD was reported. ${ }^{19}$ However. more rapid. sensitive. and reliable analytical and quantitative method for the quality control of Radix Astragali is necessary. Therefore, the aim of this study was to establish a rapid and sensitive method for the simultaneous analy'sis of three isoflavonoids (caly $\cos \sin -7-O$ $\beta$-glucoside. isomucronulatol 7-O- $\beta$-glucoside. formononetin) and two saponins (astragaloside I. astragaloside IV) (Figure 1) of Radix Astragali using HPLC/UV and LC-ESIMS/MS methods.

UV detection is a convenient and sensitive method for evaluating the isoflavonoids in Radix Astragali. However. it is difficult to detect saponins in Radix Astragali using a UV detector because of the lack of chromophore groups and the poor absorption of UV radiation. Therefore. LC-ESI-MS/ MS methods were used because they are powerful methods for rapidly identifying and elucidating the multiple-ingredients of Chinese medicine on account of their low detection limit. high specificity and structure elucidation. ${ }^{\text {(I) }}$ This study developed a rapid and sensitive analytical and quantitative method to simultaneously analyze the three isoflavonoids and two saponins in Radix Astragali using high performance liquid chromatography and tandem mass spectrometry. The proposed method was validated ${ }^{11.22}$ according to the linearity. accuracy. precision, recovery and robustness. This 
isomucronulatol $7-O-\beta$-glucoside $: \mathrm{R}=\beta$-glc<smiles>[R2]Oc1ccc2c(=O)c(-c3ccc(OC)c([R])c3)coc2c1</smiles>

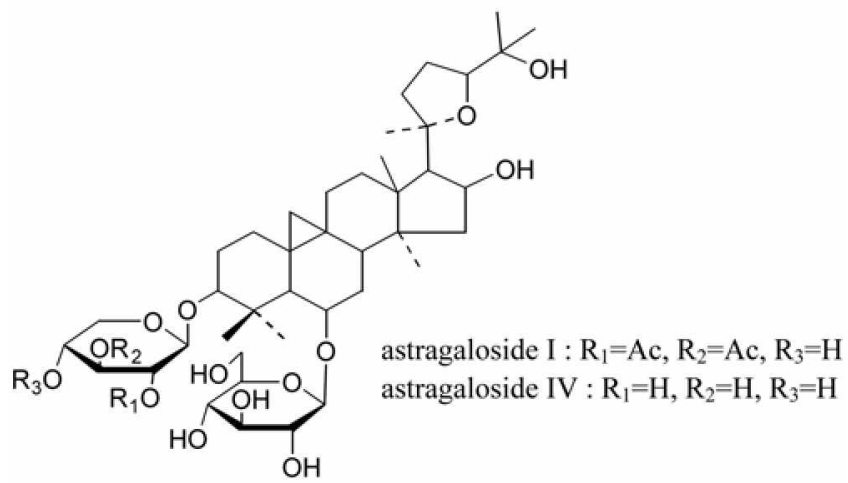

Figure 1. Molecular structures of the studed three isoflavonoids and two saponins in Radix Astragali.

method was found to be suitable for the quality control of Radix Astragali extracts and its pharmaceutical preparation.

\section{Experimental}

Materials and reagents. The powder of the dried roots of Radix Astragali. three isoflavonoids reference compounds (calycosin-7-O- $\beta$-glucoside, isonucronulatol 7-O- $\beta$-glucoside. formononetin) and two saponins (astragaloside $\mathrm{I}$. astragaloside IV) were kindly supplied by the Natural Product Research Institute. Seoul National University (Seoul. Korea). Acetonitrile. methanol and water used were of chromatographic grade (J.T. Baker. Philipsburg. MT. USA). All other reagents used were of analytical reagent grade or better.

Preparation of standard solutions. The reference compounds calycosin-7-O- $\beta$-glucoside. isonucronulatol $7-O-\beta$ glucoside, formononetin. astragaloside 1 and astragaloside IV were weighed accurately ( $2 \mathrm{mg}$ each) and dissolved in $50 \%$ acetonitrile to prepare $200 \mathrm{ppm}$ stock solutions. For the internal standard. epi-aminotadalafil (in case of HPLC/UV) and byakangelicol (in case of LC-ESI-MS/MS) were weighed accurately (10 $\mathrm{mg}$ each) and dissolved in $50 \%$ acetonitrile to prepare $1,000 \mathrm{ppm}$ stock solutions. The prepared stock solutions were degassed in an ultrasonic bath and filtered through a $0.45 \mu \mathrm{m}$ membrane. These stock solutions were diluted with $50 \%$ acetonitrile to the concentrations required in the experiment. All the solutions were stored at $4{ }^{\circ} \mathrm{C}$ before analy sis
HPLCIUV analysis. The HPLC equipment was a Waters HPLC system (Waters. Milford. MA. USA) with Waters $600 \mathrm{E}$ pumps (Waters). a Waters 2487 UV detector (Waters), a Hitachi L-2200 autosampler (Hitachi High Technologies America. San Jose. CA. USA) and a $10 \mu \mathrm{L}$ sample loop. Hypersil GOLD $(4.6 \times 250 \mathrm{~mm}, 5 \mu \mathrm{m}$. Thermo Electron Corp.. Walthan. MA, USA). Onyx Monolithic $(4.6 \times 100$ mun. Phenomenex, Torrance, CA. USA) and phenyl-hexyl $(4.6 \times 150 \mathrm{~mm}, 5 \mu \mathrm{m}$, Phenomenex. Torrance. CA, USA) columns were tested with the guard columns filled with the same stationary phase. The column temperature was set to $30^{\circ} \mathrm{C}$ using a Jasco CO-965 colum oven (Jasco. Wakayama, Japan). The mobile phase consisted of $20 \%$ acetonitrile in water (A) and $80 \%$ acetonitrile in water $(\mathrm{B})$ using a gradient elution of $0-10 \%$ B at $0-2 \mathrm{~min}, 10-40 \%$ B at $2-15 \mathrm{~min}$. 40 $100 \% \mathrm{~B}$ at $15-20 \mathrm{~min}, 100-100 \% \mathrm{~B}$ at $20-25 \mathrm{~min} .100-0 \% \mathrm{~B}$ at $25-35 \mathrm{~min}$. The mobile phase was filtered under vacuum through a $0.45 \mu \mathrm{m}$ membrane filter and degassed prior to use. The analysis was carried out at a flow rate of $1.0 \mathrm{~mL}$ min with the detection wavelength set to $230 \mathrm{~mm}$ and the injection volume was $10 \mu \mathrm{L}$. The total run time was $35 \mathrm{~min}$. The chromatograms were processed using an Autocluro2000 (Ver. 1.0 .0 ).

LC-ESI-MS/MS analysis. The Alliance 2795 HPLC system (Waters) was coupled with the Waters Quattro micro API (Waters) equipped with an ESI source with a column temperature set to $30^{\circ} \mathrm{C}$ equipped with a pump, an autosampler, a degasser. an automatic thermostatic column oven and computer software with a MassLynx (Ver. 4.1). The chromatographic separation was performed on a Capcell pak CI8 $(2.0 \times 50$ mm. $3 \mu \mathrm{m}$. Phenomenex $)$ column and a precolumn filter $(0.5 \mu \mathrm{m}$, Upchurch Scientific. Oak Harbor, WA. USA). A mixture of acetonitrile and water $(40: 60, \mathrm{v} / \mathrm{v}$ $\%$ ) was used as the mobile phase. The flow rate and the injection volume were $0.2 \mathrm{~mL} / \mathrm{min}$ and $10 \mu \mathrm{L}$, respectively.

Detection was performed by mass spectrometry in the multiple reaction monitoring mode (MRM). Ultrahigh purity argon (Ar) and high purity nitrogen $\left(\mathrm{N}_{2}\right)$ were used as the collision and the nebulizing gases. respectively. In order to tune the mass spectrometer, a $1 \mu \mathrm{g} / \mathrm{mL}$ solution of the reference compounds dissolved in $50 \%$ acetonitrile was pumped continuously into the ESI source at a rate of $10 \mu \mathrm{L}$ min using a syringe pump. The ionized chamber was set at desolvation gas flow. source temperature and desolvation temperature of $700 \mathrm{~L} / \mathrm{hr}, 120^{\circ} \mathrm{C}$ and $350^{\circ} \mathrm{C}$, respectively. The optimal collision energy and precursor ion-product ion transitions for the multiple reaction monitoring experiment. based on peak area. were optimized.

\section{Analytical method validation}

Selectivity: HPLC/UV and LC-ESI-MS/MS conditions were detemined so there would be no overlap of the bioactive compounds from the extract of Radix Astragali and good peak separation.

Linearity: The calibration curves were made by diluting the stock solutions with $50 \%$ acetonitrile. A reference solution of the three isoflavonoids (calycosin-7-O- $\beta$-glucoside, isonucronulatol 7-O- $\beta$-glucoside, formononetin) at concen- 
trations of $200-10,000 \mathrm{ng} / \mathrm{mL}$ was analyzed by HPLC/UV. while the reference solution of the bioactive compounds (calycosin-7-O- $\beta$-glucoside, formononetin. astragaloside $\mathrm{I}$. astragaloside IV) was measured at $50.750 \mathrm{ng} / \mathrm{mL}$ by LC. ESI-MS/MS. The regression equations were calculated in the form of $y=\mathrm{a} x+\mathrm{b}$. where $y$ and $x$ correspond to the peak area and conpound concentration. respectively.

Precision and accuracy: In order to confirm the reproducibility. the intra- and inter-day precision were estimated by analyzing five replicates containing the standard compounds at four different concentrations in a single day and repeating this analysis for five days, respectively. The acceptance criteria for intra- and inter-day accuracy and intra- and inter-day precision were $<15 \%$ for both bias and C.V. except at the limit of quantification (LOQ). for which accuracy and precision should be $<20 \%$.

Limits of detection and quantification: The limit of detection (LOD) is defined as the concentration of the standard solution with a signal-to-noise ratio $>3(\mathrm{~S} / \mathrm{N}>3)$. The limit of quantification (LOQ) is defined as the concentration of standard solution with a signal-to-noise ratio $>10$ $(\mathrm{S} / \mathrm{N}>10)$. The acceptance criteria for the intra-day and inter-day accuracy and precision were $<20 \%$ for both the bias and C.V.

Robustness: The robustness test is considered to be a part of the validation method associated with precision. The purpose of this test was to identify the possible sources of error in the established method that might occur due to the changes in the specified internal conditions. Robustness evaluates the influence of changes in the internal factors of the established analytical procedure. such as the variations in column temperature, flow rate and mobile phase composition, providing an indication of its reliability during normal use. In this paper. the influence of small variations on the internal parameters of this method. such as the columm temperature. flow rate and mobile phase composition were examined in triplicate for the each standard compound.

\section{Quantitative determination by HPLC/UV}

Recovery: For the preparation of the crude extract. the powders of the dried roots of Radix Astragali were sieved through a 30 mesh. The recovery test was executed by mixing a powdered root sample $(400 \mathrm{mg})$ with three control levels ( $1 \mu \mathrm{g} / \mathrm{mL}, 2 \mu \mathrm{g} / \mathrm{mL}, 3 \mu \mathrm{g} / \mathrm{mL})$ of the reference compounds. The mixture was then extracted by sonication with $10 \mathrm{~mL}$ of $70 \%$ ethanol at room temperature for $1 \mathrm{hr}$. The extract solution was filtered through a $0.45 \mu \mathrm{m}$ membrane. The HPLC/UV analysis experiments were performed in triplicate for each control level. The data was compared with those from the standard solution (assuming 100\% recovery) and extracted sample ( $400 \mathrm{mg}$ powered root samples without the reference compounds)

Quantitative determination: The powdered dried roots of eight Radix Astragali from Korea and ten Radix Astragali from China were sieved through a 30 mesh. The quantitative determination was performed by mixing the powdered root sample $(400 \mathrm{mg}$ ) with $10 \mathrm{~mL}$ of $70 \%$ ethanol. Sample preparation was performed as mentioned above.

\section{Results and Discussion}

\section{HPLC/UV analysis}

Optimization of chromatographic conditions: The HPLC conditions were selected by the requirement for obtaining the chromatograms with a better resolution of the adjacent peaks within a short retention time. The cluromatographic conditions established in this study produced baseline separation of the three isoflavonoids in Radix Astragali in a single run detected at $230 \mathrm{~nm}$. However, this method failed to detect the two saponins due to the lack of chromophores. The gradient elution of $20 \%$ acetonitrile in water and $80 \%$ acetonitrile in water at various ratios was used as the mobile phase. The ODS colunn. monolithic colunn and phenylhexyl columns were examined to determine which was most suitable. The run time of the ODS column was almost 100 $\mathrm{min}$ at $1.0 \mathrm{~mL} / \mathrm{min}$. The run time of the monolithic column was $40 \mathrm{~min}$ at $3.0 \mathrm{~mL} / \mathrm{min}$ with good separation of the $70 \%$ ethanol extract of Radix Astragali. The phenyl-hexyl column showed good separation with the shortest total run time. Figure 2 shows the representative HPLC/UV cluomatograms of the three isoflavonoids and the $70 \%$ ethanol extract of Radix Astragali. The chromatographic peaks were identified by comparing the retention time and UV spectra of the compounds in the extract with those of the standard compounds, which were eluted in parallel with a series of mobile phases.

Selectivity: The retention time of the three isoflavonoids and I.S. in the extract of Radix Astragali were $5.1 \mathrm{~min}$ (calycosin-7.0- $\beta$-glucoside). $12.1 \mathrm{~min}$ (isomucronulatol 7 -
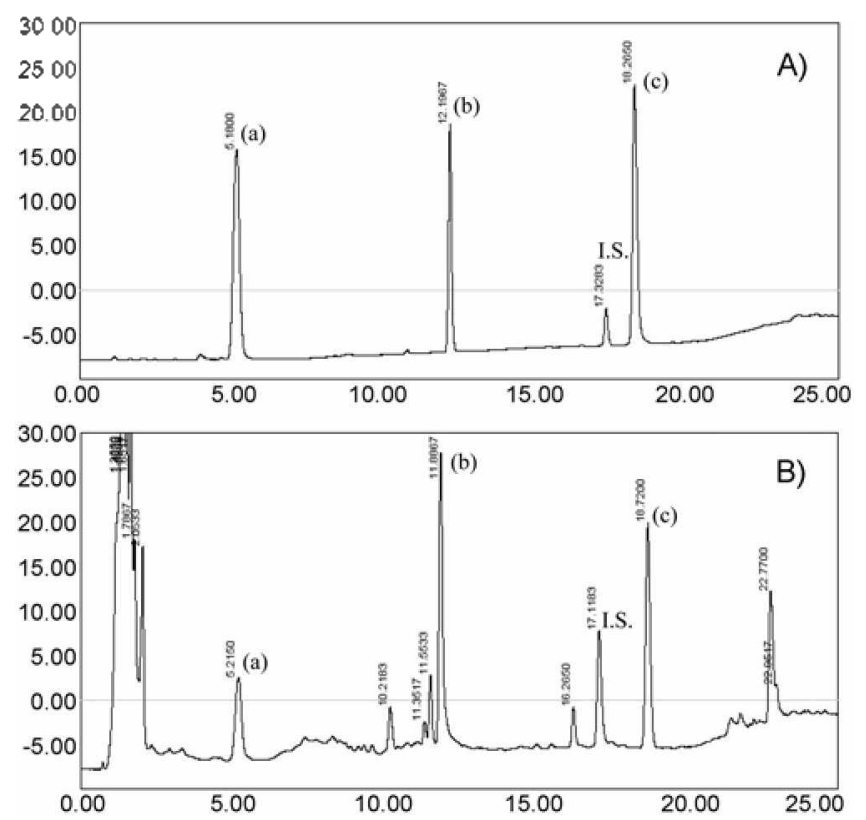

Figure 2. Chromatograms of the three isotlavonoids in Radix Astragali using the developed HPLC method. The chromatographic conditions are described in experimental section. A) Chromatogram of the reference compounds. B) Chromatograms of the $70 \%$ ethanol extract of Radix Astragali. The indicated peaks trom a to c corresponds to (a) calycosin-7-O- $\beta$-glucoside, (b) isomucronulatol 7-O- $\beta$-glucoside and (c) fonmononetin, respectively. I.S. represents the internal standard, epi-aminotadalafil. 
Table 1. Results of linear regression analysis in the determination of the three isoflavonoids using the HPLC/UV method

\begin{tabular}{|c|c|c|c|c|c|c|}
\hline \multirow{2}{*}{ Analytes } & \multirow{2}{*}{ Regression equation } & \multirow{2}{*}{$\begin{array}{c}\text { Comelation } \\
\text { coefficient }\left(\eta^{2}\right)\end{array}$} & \multicolumn{2}{|c|}{$\mathrm{LOD}(\mathrm{ng} / \mathrm{mL})$} & \multicolumn{2}{|c|}{$\mathrm{LOQ}(\mathrm{ng} / \mathrm{mL})$} \\
\hline & & & Conc. & $\mathrm{S} / \mathrm{N}$ & Conc. & $\mathrm{S} / \mathrm{N}$ \\
\hline Calycosin-7-O- $\beta$-glucoside & $y=0.001 x-0.0798$ & 0.9999 & 50 & 3.00 & 200 & 13.25 \\
\hline Isomucronulatol $7-O-\beta$-glucoside & $y=0.0006 x+0.0035$ & 0.9983 & 50 & 3.29 & 200 & 11.09 \\
\hline Formononetin & $y=0.0009 x-0.0785$ & 1.0000 & 50 & 3.16 & 200 & 10.32 \\
\hline
\end{tabular}

In the regression equation. $y=a x-b, y$ refers to the peak area and $x$ refers to the concentration of the reference compound (ng $m L$ ). LOD is the limit of detection, and $\mathrm{LOQ}$ is the limit of quantification.

$O-\beta$-glucoside). $17.3 \mathrm{~min}$ (I.S.) and $18.2 \mathrm{~min}$ (formononetin), and all peaks were well separated.

Linearity: The linearity of the peak area ratio with respect to the concentration was examined under optimal HPLC/UV conditions and is described as a regression equation. The standard curves were linear over the concentration ranges from 200 to $10.000 \mathrm{ng} / \mathrm{mL}$. The regression equation was calculated to be $y=0.001 x-0.0798$ for calycosin-7-O- $\beta$ glucoside, $y=0.0006 x+0.0035$ for isomucronulatol 7-O- $\beta$ glucoside and $y=0.0009 x-0.0785$ for formononetin. in where $y$ and $x$ correspond to the peak area and concentration of each compound ( $\mathrm{ng} / \mathrm{mL}$ ), respectively (Table 1). Each coefficient of determination $(r)$ was $>0.9983$. as determined by least square analysis. suggesting good linearity between the peak areas $(v)$ and the compound concentrations $(x)$ over a wide concentration range.

Precision and accuracy: Table 2 shows the precision and accuracy of the three isoflavonoids from Radix Astragali determined in the intra- and inter-day trials $(n=5)$. The results show intra-day and inter-day precision of $0.70-9.39 \%$ and $2.55-19.76 \%$. respectively. The intra-day and inter-day accuracy of the three isoflavonoids are $91.6-110.0 \%$ and $94.3-107.1 \%$, respectively. This indicates that the developed HPLC method is accurate and precise for the simultaneous evaluation of the three active isoflavonoids in Radix Astragali.

Limits of detection and yuantification: The LODs (S/N $>3$ ) of the three isoflavonoids were $50 \mathrm{ng} / \mathrm{mL}$. which indicated high sensitivity under these HPLC conditions. In

Table 2. Intra-, inter-day precision and accuracy of the bioactive components in Radix Astragali using HPLC/UV method $(\mathrm{n}=5$ )

\begin{tabular}{|c|c|c|c|c|c|}
\hline \multirow[b]{2}{*}{ Analytes } & \multirow{2}{*}{$\begin{array}{l}\text { Conc. } \\
(\mathrm{ng} / \mathrm{mL})\end{array}$} & \multicolumn{2}{|c|}{ Intra-Day } & \multicolumn{2}{|c|}{ Inter-Day } \\
\hline & & $\begin{array}{l}\text { Precision } \\
\text { (C.V. \%) }\end{array}$ & $\begin{array}{c}\text { Accuracy } \\
(\%)\end{array}$ & $\begin{array}{l}\text { Precision } \\
\text { (C V. \%) }\end{array}$ & $\begin{array}{c}\text { Accuracy } \\
(\%)\end{array}$ \\
\hline \multirow{4}{*}{$\begin{array}{l}\text { Calycosin- } \\
7-O-\beta \text {-glucoside }\end{array}$} & 200 & 7.40 & 108.3 & 14.13 & 103.6 \\
\hline & 500 & 6.08 & 91.6 & 7.25 & 95.2 \\
\hline & 1000 & 3.75 & 94.4 & 3.97 & 99.1 \\
\hline & 10000 & 1.66 & 93.5 & 4.77 & 101.0 \\
\hline \multirow{4}{*}{ 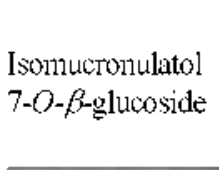 } & 200 & 9.39 & 108.0 & 19.76 & 101.1 \\
\hline & 500 & 4.71 & 101.7 & 4.51 & 100.0 \\
\hline & 1000 & 5.01 & 100.0 & 5.14 & 97.9 \\
\hline & 10000 & 4.09 & 95.5 & 4.15 & 99.9 \\
\hline \multirow{4}{*}{ Fomononetin } & 200 & 3.32 & 110.0 & 7.29 & 107.1 \\
\hline & 500 & 5.41 & 97.5 & 2.55 & 97.4 \\
\hline & 1000 & 0.70 & 97.6 & 2.62 & 94.3 \\
\hline & 10000 & 2.78 & 94.9 & 3.20 & 95.4 \\
\hline
\end{tabular}

addition, the LOQs $(\mathrm{S} / \mathrm{N}>10)$ of the three isoflavonoids were $200 \mathrm{ng} / \mathrm{mL}$. This shows that the acceptance criteria for the intra- and inter-day accuracy and intra- and inter-day precision were $<20 \%$ for both the bias and $\mathrm{C}$. V.

Robustness: The robustness was detemined in order to evaluate the reliability of the established HPLC methods. Briefly, the experimental conditions, such as the column temperature, flow rates and composition of the mobile phase were purposely altered. The area precision (C.V.). relative retention time (RRT), peak tailing factor $(\mathrm{T})$ and theoretical

Table 3. The robustress test for the HPLC/UV method ( $\mathrm{n}=3$ )

\begin{tabular}{|c|c|c|c|c|c|c|}
\hline Analytes & \multicolumn{2}{|c|}{ Conditions } & C.V. & RRT & $\mathrm{T}$ & $\mathrm{N}$ \\
\hline \multirow{9}{*}{$\begin{array}{l}\text { Calycosin- } \\
7-O-\beta \text {-glucoside }\end{array}$} & \multirow{3}{*}{$\begin{array}{c}\text { Temperature } \\
\text { ("C) }\end{array}$} & 30 & 0.91 & 0.31 & 0.95 & 2256 \\
\hline & & 35 & 7.06 & 0.31 & 1.15 & 2382 \\
\hline & & 40 & 1.90 & 0.30 & 1.16 & 2295 \\
\hline & \multirow{3}{*}{$\begin{array}{l}\text { Flow rate } \\
(\mathrm{mL} / \mathrm{min})\end{array}$} & 0.9 & 0.42 & 0.33 & 0.93 & 3344 \\
\hline & & $|s\rangle$ & 0.91 & 0.31 & 0.95 & 2672 \\
\hline & & 11 & 0.39 & 0.31 & 1.06 & 2361 \\
\hline & \multirow{3}{*}{$\begin{array}{l}\text { Gradient } \\
\text { Frofile" }\end{array}$} & (a) & 7.11 & 0.28 & 1.08 & 2511 \\
\hline & & (b) & 0.91 & 0.31 & 0.95 & 2256 \\
\hline & & (c) & 2.75 & 0.33 & 1.10 & 2555 \\
\hline \multirow{9}{*}{$\begin{array}{l}\text { Isomucronulatol } \\
7-O-\beta \text {-glucoside }\end{array}$} & \multirow{3}{*}{$\begin{array}{c}\text { Temperature } \\
\text { ('C) }\end{array}$} & 30 & 2.41 & 0.71 & 1.01 & 39343 \\
\hline & & 35 & 7.96 & 0.71 & 1.23 & 37300 \\
\hline & & 40 & 4.21 & 0.71 & 1.14 & 34280 \\
\hline & \multirow{3}{*}{$\begin{array}{l}\text { Flow rate } \\
(\mathrm{mL} / \mathrm{min})\end{array}$} & 0.9 & 1.15 & 0.71 & 1.15 & 40966 \\
\hline & & 1.8 & 2.41 & 0.71 & 1.01 & 39343 \\
\hline & & 11 & 3.88 & 0.68 & 1.26 & 29890 \\
\hline & \multirow{3}{*}{$\begin{array}{l}\text { Gradient } \\
\text { profile }\end{array}$} & (a) & 3.42 & 0.65 & 1.31 & 39609 \\
\hline & & (b) & 2.41 & 0.71 & 1.01 & 39343 \\
\hline & & (c) & 3.48 & 0.74 & 1.16 & 60681 \\
\hline \multirow{9}{*}{ Formononetin } & \multirow{3}{*}{$\begin{array}{c}\text { Temperature } \\
\text { ( } \mathrm{C} \mathrm{C})\end{array}$} & 30 & 2.02 & 1.05 & 1.52 & 40809 \\
\hline & & 35 & 2.42 & 1.05 & 1.27 & 49660 \\
\hline & & 40 & 3.22 & 1.04 & 1.31 & 36051 \\
\hline & \multirow{3}{*}{$\begin{array}{l}\text { Flow rate } \\
(\mathrm{mL} / \mathrm{min})\end{array}$} & 0.9 & 1.96 & 1.06 & 1.56 & 49816 \\
\hline & & 10 & 2.02 & 1.05 & 1.52 & 40809 \\
\hline & & 11 & 1.08 & 1.06 & 1.35 & 43260 \\
\hline & \multirow{3}{*}{$\begin{array}{l}\text { Gradient } \\
\text { protile? }\end{array}$} & (a) & 3.85 & 1.05 & 1.41 & +4132 \\
\hline & & (b) & 2.02 & 1.05 & 1.52 & 40829 \\
\hline & & (c) & 2.49 & 105 & 1.25 & 55097 \\
\hline
\end{tabular}

C.V. represents the area precision. RK'l represents the relatit e retention time. 'I represents the peak tailing factor and $\mathrm{N}$ represents the theoretical plate number. : Gradient profile is as follows: (a) $10-30^{\circ} .{ }_{0} \mathrm{~B}$ at $2-15 \mathrm{~min}$ (b) $10-40^{\circ}, \mathrm{B}$ at $2-15 \mathrm{~min}$ (c) $10-50^{\circ} \circ \mathrm{B}$ at $2-15 \mathrm{~min}$ and the others are same as shown in the above text. 
plate number $(N)$ were then evaluated. The changes in column temperature and flow rates were $35 \pm 5^{\circ} \mathrm{C}$, and $1.0 \pm$ $0.1 \mathrm{~mL} / \mathrm{min}$. respectively. All the results listed in Table 3 show the average of at least three independent experiments. The area precision (C.V) was $<7.96 \%$ and the other parameters were maintained so there would not be any interference with the other peaks for the Radix Astragali extract.

\section{LC-ESI-MS/MS Analysis}

Optimization of chromatographic separation conditions: For LC-ESI-MS/MS analysis, a Waters $2795 \mathrm{HPLC}$ system was connected to Waters Quattro micro API system. The best conditions for ionizing the active constituents in Radix Astragali in the mass spectrometer were obtained with ESI positive ionization mode using a mixture of acetonitrile and water $(40: 60, v / v \%)$ as the mobile phase. How- ever, it was difficult to detect isomucromulatol $7-0$ - $\beta$-glucoside in Radix Astragali using LC-ESI-MS/MS due to a lack of ionization. Figure 3 shows the mass spectra produced by LC-ESI-MS/MS under the above mentioned chromatographic conditions. In the mass spectra, the $[\mathrm{M}+\mathrm{H}]^{+}$of the two isoflavonoid and $[\mathrm{M}+\mathrm{Na}]^{-}$of the two saponins can be easily observed. In the $\mathrm{MS}^{2}$ spectra, the fragment ions indicating the loss of glucose. xy lose and $\mathrm{CH}_{3} \mathrm{OH}$ were observed.

The molecular ions of calycosin-7-O- $\beta$-glucose, formononetin. astragaloside I, astragaloside IV and byakangelicol were fragmented at collision energy of $25,38,90.90$ and 26 $\mathrm{eV}$. respectively. Figure 4 shows the multiple reaction monitoring (MRM) cluromatogrants of calycosin-7-0- $\beta$-glucose at $m z 285.0$ from the MS/MS scan precursor ion at $m z$ 446.9, fonmononetin with $m z 268.9 \rightarrow 197.0$. astragaloside I

A)

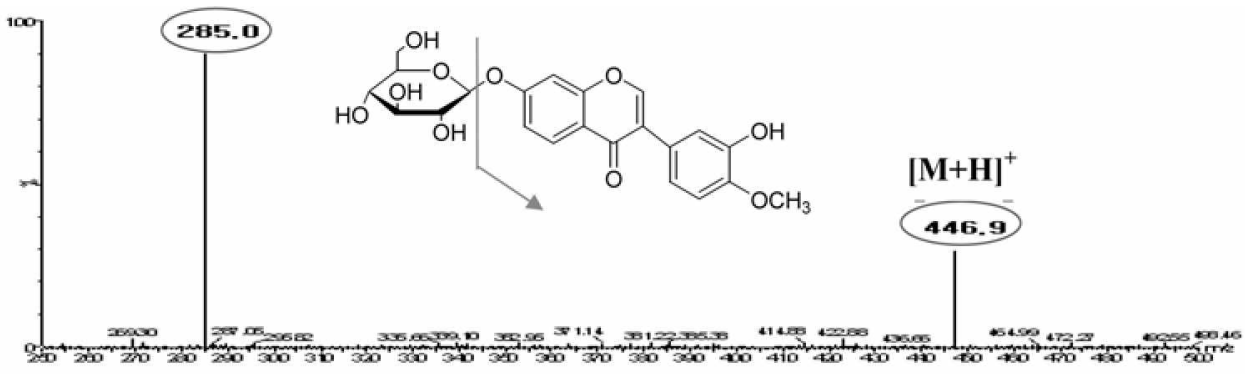

B)

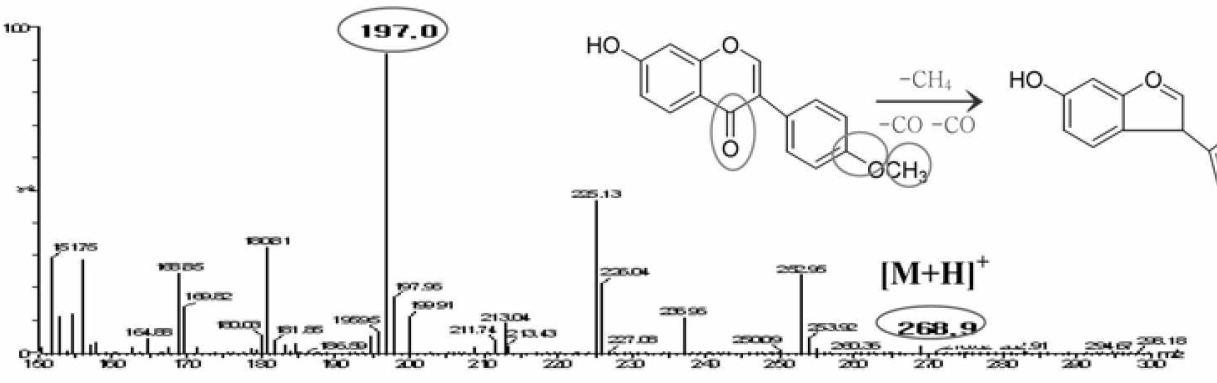

C)

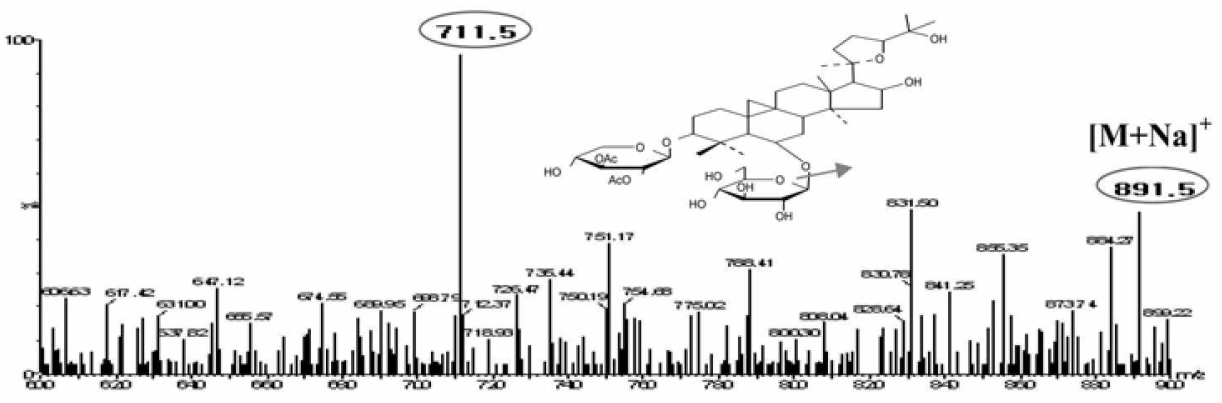

D)

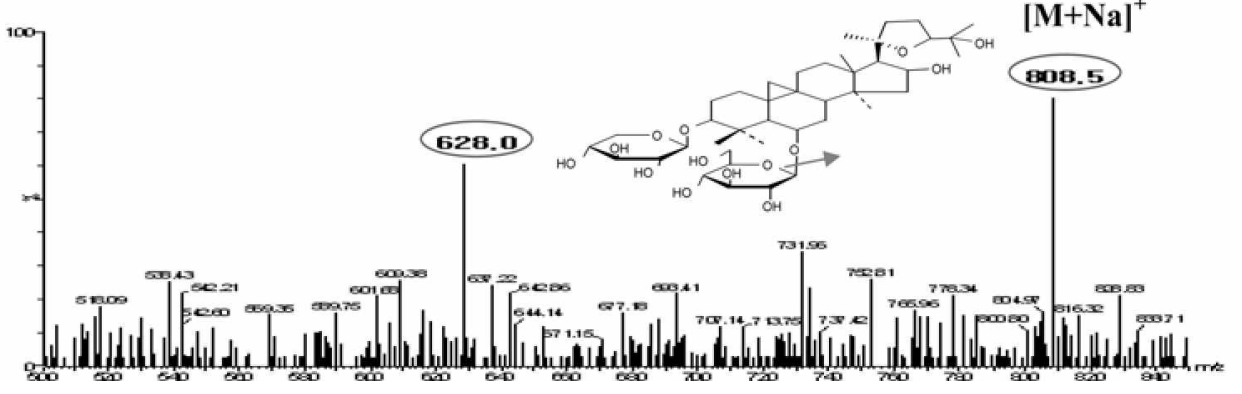

Figure 3. Mass spectra of A) calycosin-7-O- $\beta$-glucoside, B) fonononetin, C) astragaloside I and D) astragaloside IV produced by LC-ESIMS/MS. 

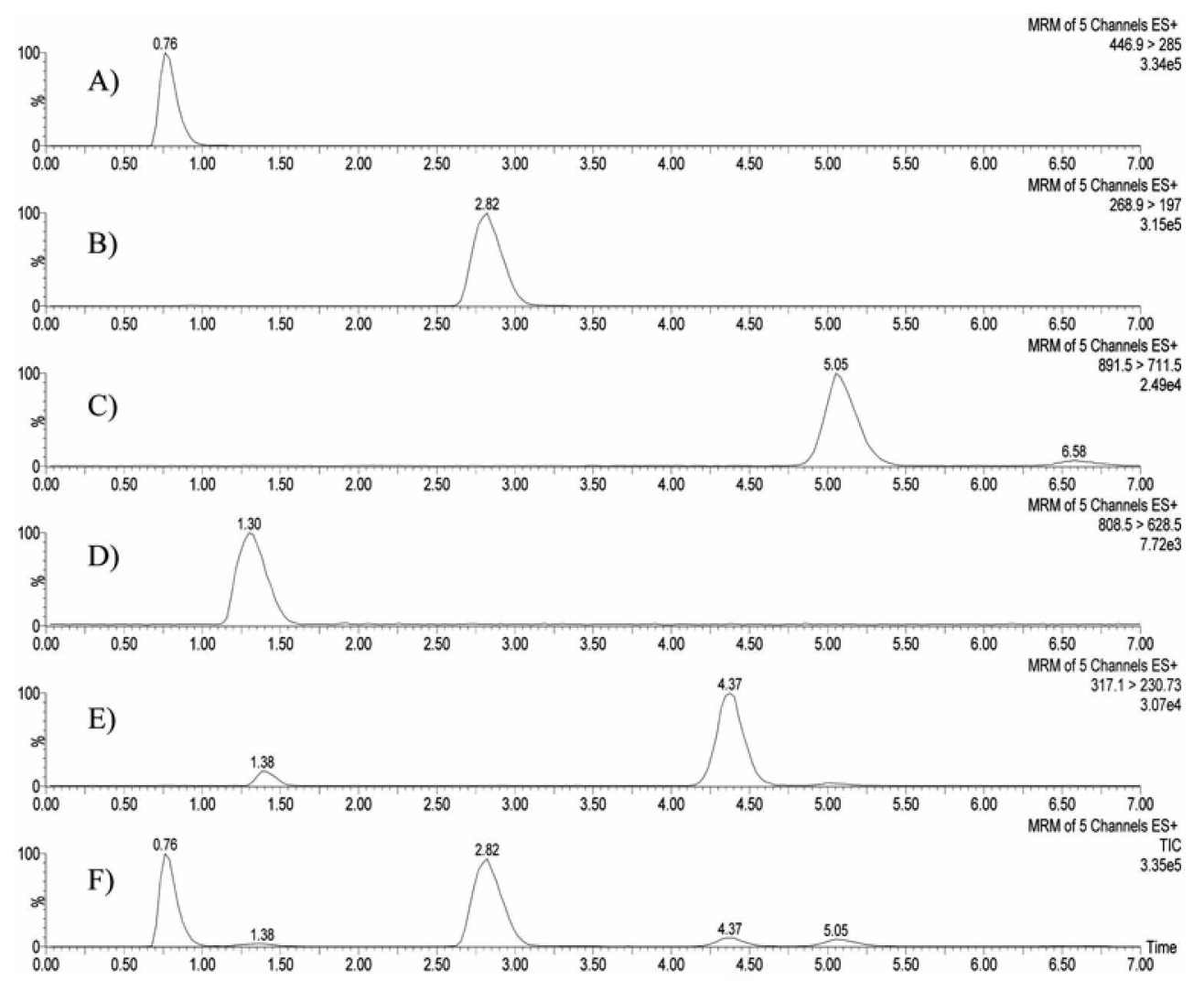

Figure 4. LC-ESI-MS/MS chromatograms of A) calycosin-7-O- $\beta$-glucoside, B) formononetin, C) astragaloside I, D) astragaloside IV, E) brakangelicol (I.S.) and F) total ion chromatogram (TIC).

with $m z 891.5 \rightarrow 711.5$. astragaloside IV with $m z 808.5 \rightarrow$ 628.0 and byakangelicol (I.S.) with $m z 317.1 \rightarrow 230.7$. The peaks obtained for all compounds using the LC-ESI-MS/MS technique had good shapes with good separation. Under these conditions, two isoflavonoids, two saponins and an internal standard. byakangelicol were analyzed within $7 \mathrm{~min}$.

Selectivity: The retention times for the extract of Radix Astragali were $0.76 \mathrm{~min}$ (calycosin-7- $O$ - $\beta$-glucoside). 1.30 min (astragaloside IV). $2.82 \mathrm{~min}$ (formononetin). $5.05 \mathrm{~min}$ (astragaloside I) and $4.37 \mathrm{~min}$ (I.S.), and all peaks were well separated.

Linearity: The linearity of the peak area ratio with respect to the concentration using the developed LC-ESI-MS/MS method was examined and the results are shown as a regression equation. The standard curves were linear over the concentration ranges from 50 to $750 \mathrm{ng} / \mathrm{mL}$. The regression equation was $y=0.0114 x+0.4142$ for calycosin-7-O- $\beta$ - glucoside. $y=0.0170 x+2.0764$ for fomononetin, $y=$ $0.0017 x-0.0576$ for astragaloside $I$ and $y=0.0005 x-$ 0.0156 for astragaloside IV, in where $y$ and $x$ correspond to the peak area and concentration of each compound $(\mathrm{ng} / \mathrm{mL})$. respectively. The high correlation $\left(r^{2}>0.9913\right)$ indicates good linearity between the peak areas $(v)$ and concentrations $(x)$ over a relatively wide concentration range (Table 4 ).

Precision and accuracy: Table 5 shows the intra-day and inter-day $(n=5)$ precision and accuracy of the two isoflavonoids and two saponins from Radix Astragali. The data shows that the intra-day and inter-day precision were 1.05 $5.24 \%$ and $3.77-19.77 \%$. respectively. The intra-day and inter-day accuracy of the two isoflavonoids and two saponins were $86.8-117.6 \%$ and $87.0-116.2 \%$, respectively. This indicates that the developed LC-ESI-MS/MS method is accurate and precise for the simultaneous evaluation of the two isoflavonoids and two saponins in Radix Astragali.

Table 4. Results of linear regression analysis of the LC-ESI-MS/MS method

\begin{tabular}{|c|c|c|c|c|c|c|}
\hline \multirow{2}{*}{ Analytes } & \multirow{2}{*}{ Regression equation } & \multirow{2}{*}{$\begin{array}{c}\text { Conrelation } \\
\text { coefticient }\left(r^{2}\right)\end{array}$} & \multicolumn{2}{|c|}{ LOD (ng/mL) } & \multicolumn{2}{|c|}{$\mathrm{LOQ}(\mathrm{ng} / \mathrm{mL})$} \\
\hline & & & Conc. & $\mathrm{S} / \mathrm{N}$ & Conc. & $\mathrm{S} / \mathrm{N}$ \\
\hline Calycosin-7-O- - glucoside & $y=0.0114 x+0.4142$ & 0.9949 & 1.25 & 3.97 & 50 & 35.52 \\
\hline Fonmononetin & $y=0.0170 x+2.0764$ & 0.9980 & 1.25 & 3.66 & 50 & 32.70 \\
\hline Astragaloside I & $y=0.0017 x-0.0576$ & 0.9920 & 1.25 & 3.66 & 50 & 15.32 \\
\hline Astragaloside IV & $y=0.0005 x-0.0156$ & 0.9913 & 1.25 & 3.97 & 50 & 14.26 \\
\hline
\end{tabular}

In the regression equation, $y=a x-b, y$ reters to the peak area. $x$ refers to concentration of the reterence compound (ng mL). LOD is the limit of detection and $L O Q$ is the limit of quantification. 
Table 5. Intra-, inter-day precision and accuracy of the bioactive components in Radix Astragali using LC-ESI-MS/MS method $(\mathbf{n}=5)$

\begin{tabular}{|c|c|c|c|c|c|}
\hline \multirow[b]{2}{*}{ Analytes } & \multirow{2}{*}{$\begin{array}{c}\text { Conc. } \\
\text { (ng } / n 2 L)\end{array}$} & \multicolumn{2}{|c|}{ Intra-Day } & \multicolumn{2}{|c|}{ Inter-Day } \\
\hline & & $\begin{array}{l}\text { Precision } \\
\text { (C.V. \%) }\end{array}$ & $\begin{array}{c}\text { Accuracy } \\
(\%)\end{array}$ & $\begin{array}{l}\text { Precision } \\
\text { (C.V.\%) }\end{array}$ & $\begin{array}{c}\text { Accuracy } \\
1 \% \mathrm{j}\end{array}$ \\
\hline \multirow{4}{*}{$\begin{array}{l}\text { Calycosin- } \\
7-O-\beta \text {-glucoside }\end{array}$} & 50 & 1.65 & 86.8 & 18.66 & 90.8 \\
\hline & 100 & 2.32 & 88.2 & 8.46 & 103.6 \\
\hline & 250 & 2.45 & 90.2 & 13.56 & 87.9 \\
\hline & 750 & 3.44 & 87.5 & 14.71 & 950 \\
\hline \multirow{4}{*}{ Fonmononetin } & 50 & 1.05 & 105.3 & 19.77 & 97.8 \\
\hline & 100 & 2.18 & 98.5 & 6.77 & 99.9 \\
\hline & 250 & 1.41 & 112.2 & 5.84 & 101.0 \\
\hline & 750 & 4.53 & 98.1 & 13.16 & 93.4 \\
\hline \multirow{4}{*}{ Astragaloside I } & 50 & 2.71 & 116.2 & 7.74 & 116.2 \\
\hline & 100 & 3.11 & 90.5 & 3.77 & 87.0 \\
\hline & 250 & 2.98 & 109.9 & 4.98 & 93.6 \\
\hline & 750 & 1.74 & 113.2 & 7.25 & 111.3 \\
\hline \multirow{4}{*}{ Astragaloside IV } & 50 & 3.51 & 117.6 & 7.48 & 115.3 \\
\hline & 100 & 2.64 & 95.2 & 6.49 & 91.2 \\
\hline & 250 & 1.51 & 112.3 & 8.84 & 111.9 \\
\hline & 750 & 5.24 & 108.1 & 9.73 & 100.5 \\
\hline
\end{tabular}

Limits of detection and quantification: The LODs (S/N $>3$ ) of the two isoflavonoids and two saponins were 1.25 $\mathrm{ng} / \mathrm{mL}$ and $12.5 \mathrm{ng} / \mathrm{mL}$, respectively. which indicates a high sensitivity under these LC-ESI-MS/MS conditions. The LOQs ( $\mathrm{S} / \mathrm{N}>10$ ) of the two isoflavonoids and two saponins were $50 \mathrm{ng} / \mathrm{mL}$, which show that the acceptance criteria for intra- and inter-day accuracy and intra- and inter-day precision were $<20 \%$ for both the bias and $\mathrm{C} . \mathrm{V}$.

Robustness: The reliability of the established LC-ESIMS/MS methods was examined by testing the robustness. Briefly, the experimental conditions, such as colunn temperature, flow rates and composition of the mobile phase, were altered purposely. The area precision (C.V.). relative retention time (RRT), peak tailing factor ( $\mathrm{T}$ ) and theoretical plate number $(\mathrm{N})$ were evaluated. The changes in the column temperature and flow rates were $35 \pm 5^{\circ} \mathrm{C}$ and $200 \pm 20 \mu \mathrm{L} /$ min. respectively. The changes in the mobile phase were 40 $\pm 2 \%$ acetonitrile. All the results listed in Table 6 are the average of at least three independent experiments. The area precision (C.V.) was $<12.08 \%$ and the other parameters were maintained so there would not be any interference with the other peaks in the Radix Astragali extract. Based on these results. the LC-ESI-MS/MS method developed in this study was found to be acceptable for the simple. rapid and simultaneous determination of the two isoflavonoids and two saponins in Radix Astragali.

\section{Quantitative determination by HPLC/UV}

Recovery: The extraction recovery test was performed by extracting a known amount of the isoflaxonoids from the Radix Astragali powder samples. A known amount of each standard compound at three different levels was mixed with the sample powder and extracted. as described in the experimental section. The \% recovery of each standard ranged from 96.56 to $99.27 \%$. and the RSD was $<3.0 \%$ (Table 7 ).
Table 6. Results of the robustness test of the LC-ESI-MS/MS $\operatorname{method}(\mathbf{n}=3)$

\begin{tabular}{|c|c|c|c|c|c|c|}
\hline Analytes & Analytical & Condition & C.V. & RRT & $\mathrm{T}$ & $\bar{N}$ \\
\hline \multirow{9}{*}{$\begin{array}{l}\text { Calycosin- } \\
7-O-\beta \text { - } \\
\text { glucoside }\end{array}$} & \multirow{3}{*}{ lemperature } & $30^{\circ} \mathrm{C}$ & 3.48 & 0.18 & 1.13 & 98 \\
\hline & & $35^{\circ} \mathrm{C}$ & 3.02 & 0.19 & 1.33 & 129 \\
\hline & & $40^{\circ} \mathrm{C}$ & 3.25 & 0.20 & 1.41 & 180 \\
\hline & \multirow{3}{*}{ Flow rate } & $180 \mathrm{uL} / \mathrm{min}$ & 10.3 & 0.18 & 1.29 & 144 \\
\hline & & $200 \mathrm{uL} / \mathrm{min}$ & 5.34 & 0.18 & 1.22 & 200 \\
\hline & & $220 \mathrm{uL} / \mathrm{min}$ & 5.20 & 0.18 & 1.49 & 171 \\
\hline & \multirow{3}{*}{$\begin{array}{l}\text { Gradient } \\
\text { Protile }\end{array}$} & $38 \%$ & 1.25 & 0.17 & 1.45 & 185 \\
\hline & & $40 \%$ & 5.75 & 0.18 & 1.21 & 157 \\
\hline & & $42 \%$ & 2.32 & 0.17 & 1.39 & 140 \\
\hline \multirow{9}{*}{$\begin{array}{l}\text { Formono- } \\
\text { netin }\end{array}$} & \multirow{3}{*}{ lemperature } & $30^{\circ} \mathrm{C}$ & 2.30 & 0.64 & 1.70 & 675 \\
\hline & & $35^{\circ} \mathrm{C}$ & 1.43 & 0.64 & 1.65 & 622 \\
\hline & & $40^{\circ} \mathrm{C}$ & 3.34 & 0.64 & 1.50 & 670 \\
\hline & \multirow{3}{*}{ Flow rate } & $180 \mathrm{uL} / \mathrm{min}$ & 12.08 & 0.64 & 1.48 & 690 \\
\hline & & $200 \mathrm{uL} / \mathrm{min}$ & 5.26 & 0.64 & 1.39 & 709 \\
\hline & & $220 \mathrm{uL} / \mathrm{min}$ & 3.17 & 0.64 & 1.72 & 665 \\
\hline & \multirow{3}{*}{$\begin{array}{l}\text { Gradient } \\
\text { profile }\end{array}$} & $38 \%$ & 0.24 & 0.64 & 1.37 & 775 \\
\hline & & $40 \%$ & 3.08 & 0.64 & 1.41 & 683 \\
\hline & & $42 \%$ & 1.87 & 0.64 & 1.61 & 631 \\
\hline \multirow{9}{*}{$\begin{array}{l}\text { Astragalo- } \\
\text { side I }\end{array}$} & \multirow{3}{*}{ lemperature } & $30^{\circ} \mathrm{C}$ & 2.65 & 1.16 & 1.28 & 1621 \\
\hline & & $35^{\circ} \mathrm{C}$ & 2.36 & 1.35 & 1.27 & 2224 \\
\hline & & $40^{\circ} \mathrm{C}$ & 0.34 & 1.53 & 1.46 & 2368 \\
\hline & \multirow{3}{*}{ Flow rate } & $180 \mathrm{uL} / \mathrm{min}$ & 0.88 & 1.16 & 1.51 & 1978 \\
\hline & & $200 \mathrm{uL} / \mathrm{min}$ & 1.29 & 1.17 & 1.58 & 1608 \\
\hline & & $220 \mathrm{uL} / \mathrm{min}$ & 5.82 & 1.17 & 1.37 & 1952 \\
\hline & \multirow{3}{*}{$\begin{array}{l}\text { Gradient } \\
\text { profile }\end{array}$} & $38 \%$ & 0.34 & 1.25 & 1.43 & 1436 \\
\hline & & $40 \%$ & 2.46 & 1.16 & 1.39 & 1735 \\
\hline & & $42 \%$ & 0.77 & 1.23 & 1.20 & 1260 \\
\hline \multirow{9}{*}{$\begin{array}{l}\text { Astragalo- } \\
\text { side IV }\end{array}$} & \multirow{3}{*}{ lemperature } & $30^{\circ} \mathrm{C}$ & 1.49 & 0.31 & 1.19 & 110 \\
\hline & & $35^{\circ} \mathrm{C}$ & 0.28 & 0.35 & 1.56 & 168 \\
\hline & & $40^{\circ} \mathrm{C}$ & 0.97 & 0.40 & 1.38 & 363 \\
\hline & \multirow{3}{*}{ Flow rate } & $180 \mathrm{uL} / \mathrm{min}$ & 7.40 & 0.31 & 1.06 & 132 \\
\hline & & $200 \mathrm{uL} / \mathrm{min} 1$ & 2.30 & 0.31 & 1.11 & 115 \\
\hline & & $220 \mathrm{uL} / \mathrm{minl}$ & 5.76 & 0.30 & 1.38 & 149 \\
\hline & \multirow{3}{*}{$\begin{array}{l}\text { Gradient } \\
\text { profile }\end{array}$} & $38 \%$ & 2.59 & 0.30 & 1.52 & 88 \\
\hline & & $40 \%$ & 6.22 & 0.30 & 0.91 & 122 \\
\hline & & $42 \%$ & 5.30 & 0.30 & 1.52 & 95 \\
\hline
\end{tabular}

C.V. represents the area precision. RRT represents the relative retention time. T represents the peak tailing factor and $\mathrm{N}$ represents the theoretical plate number

The average recovery is represented by the formula: $\mathrm{R}(\%)=$ [amount from the root sample spiked standard - amount from the root sample)/amount from the spiked standard] $\times 100$.

Analysis of Radix Astragali: The developed HPLC/UV method was then applied to the simultaneous determination of the three major isoflavonoids. calycosin-7-O- $\beta$-glucoside, isomucronulatol 7-O- $\beta$-glucoside and formononetin, in the Radix Astragali extract. Figure 2 shows chromatogram of the reference compounds and the $70 \%$ ethanol extract of Radix Astragali. As shown in Figure 2b. there was good chromatographic separation of the isoflavonoids in the extract of Radix Astragali using the established method. Eighteen commercially available Radix Astragali samples were obtained from Korea and China. Table 8 sunmmarized the concen- 
Table 7. Results of the recovery test by HPLC/UV

\begin{tabular}{|c|c|c|c|c|c|c|}
\hline \multirow{2}{*}{ Analytes } & \multirow{2}{*}{$\begin{array}{l}\text { Spiked } \\
\text { grade }\end{array}$} & \multicolumn{3}{|c|}{ Recovery (\%) } & \multirow{2}{*}{$\begin{array}{l}\text { Recovery } \\
\text { mean }(\%)\end{array}$} & \multirow{2}{*}{$\begin{array}{l}\text { RSD } \\
(\%)\end{array}$} \\
\hline & & 1 & 2 & 3 & & \\
\hline \multirow{3}{*}{$\begin{array}{l}\text { Calycosin- } \\
7-O-\beta \text {-glucoside }\end{array}$} & Low & 95.66 & 94.72 & 99.29 & 96.56 & 2.41 \\
\hline & Middle & 99.70 & 99.63 & 98.48 & 99.27 & 0.68 \\
\hline & High & 99.48 & 98.68 & 99.33 & 99.16 & 0.42 \\
\hline \multirow{3}{*}{$\begin{array}{l}\text { Isomucronulatol } \\
7-O-\beta \text {-glucoside }\end{array}$} & Low & 95.85 & 96.06 & 99.49 & 97.13 & 2.05 \\
\hline & Middle & 99.40 & 98.76 & 97.64 & 98.60 & 0.89 \\
\hline & High & 97.41 & 96.97 & 95.92 & 96.77 & 0.77 \\
\hline \multirow{3}{*}{ Fonmononetin } & Low & 99.62 & 96.59 & 98.47 & 98.22 & $1.5 \hat{3}$ \\
\hline & Middle & 96.83 & 99.26 & 96.71 & 97.60 & 1.44 \\
\hline & High & 97.43 & 97.84 & 99.74 & 98.34 & 1.23 \\
\hline
\end{tabular}

tLow: $1, \mu \mathrm{gmL}$. Middle: $2 \mu \mathrm{g} \mathrm{mL}$. High: $3 \mu \mathrm{g} \mathrm{mL}$

Table 8. Quantitative analytical results of the various Radix Astragali samples

\begin{tabular}{|c|c|c|c|}
\hline \multirow[b]{2}{*}{$\mathrm{No}^{*}$} & \multicolumn{3}{|c|}{ Mean concentrations of compounds $\left(\mu \mathrm{g} / \mathrm{g}^{-}\right)$} \\
\hline & $\begin{array}{c}\text { Calycosin- }-7-O-\beta- \\
\text { glucoside }\end{array}$ & $\begin{array}{l}\text { lsomucronulatol } \\
7-O-\beta \text {-glucoside }\end{array}$ & Fomononetin \\
\hline $\mathrm{Kl}$ & 207.02 & 198.06 & 37.54 \\
\hline $\mathrm{K} 2$ & 100.01 & 97.76 & 20.32 \\
\hline $\mathrm{K} 3$ & 44.64 & 84.20 & 27.21 \\
\hline $\mathrm{K} 4$ & 125.82 & 40.00 & 144.25 \\
\hline $\mathrm{K} 5$ & 215.95 & 223.44 & 37.90 \\
\hline $\mathrm{K} 6$ & 396.90 & 97.82 & 67.14 \\
\hline $\mathrm{K} 7$ & 98.49 & 77.68 & 43.56 \\
\hline $\mathrm{K} 8$ & 295.72 & 96.17 & 63.99 \\
\hline $\mathrm{Cl}$ & 116.81 & 64.16 & 83.09 \\
\hline $\mathrm{C} 2$ & 265.25 & 154.35 & 97.37 \\
\hline $\mathrm{C} 3$ & 169.62 & 47.13 & 69.56 \\
\hline $\mathrm{C} 4$ & 27.28 & 46.63 & 364.65 \\
\hline $\mathrm{C} 5$ & 75.51 & 43.32 & 255.77 \\
\hline $\mathrm{C} 6$ & 230.93 & 63.02 & 135.64 \\
\hline $\mathrm{C} 7$ & 193.84 & 18.81 & 85.26 \\
\hline $\mathrm{CB}$ & 144.69 & 26.71 & 134.51 \\
\hline $\mathrm{Cg}$ & 127.23 & 28.70 & 331.10 \\
\hline $\mathrm{ClO}$ & 28.60 & 42.38 & N.D. \\
\hline
\end{tabular}

"Reters to dry weight of Radix Astragali. N.D.: not detected. No": " $K$ " refers to Radix Astragali of Korea and "C" refers to Radix Astragali of China.

trations $(\mu \mathrm{g} / \mathrm{g})$. The data presented in Table 8 shows that the concentrations of three isoflavonoids. calycosin-7-O- $\beta$ glucoside, isonucronulatol 7-O- $\beta$-glucoside, and formononetin in the extract of Korean Radix Astragali were 44.64$396.90 \mu \mathrm{g} / \mathrm{g}$. 39.97-223.44 $\mu \mathrm{g} / \mathrm{g}$. and 20.32-144.25 $\mu \mathrm{g} / \mathrm{g}$. respectively. The anounts of those isoflavonoids in the extract of Chinese Radix Astragali were 27.28-265.25 $\mu \mathrm{g} / \mathrm{g}$. $18.81-154.35 \mu \mathrm{g} / \mathrm{g}$. and $69.56-364.65 \mu \mathrm{g} / \mathrm{g}$. respectively. The formononetin was not detected in " $\mathrm{C} 10$ " (number 10 . the Radix Astragali of China)

\section{Conclusions}

Many papers have reported that isoflavonoids and saponins are the active constituents in Radix Astragali responsible for its biological activities. Therefore. techniques for the simultaneous quantitative and qualitative analỵsis of Radix Astragali are of great importance. This study examined the feasibility of HPLC/UV and LC.ESI-MS/MS methods in evaluating the quality and quantity of Radix Astragali. These methods successfully analyzed and quantified the three isoflavonoids and two saponins from Radix Astragali. The baseline separation of the three isoflavonoids and short analysis time were achieved using the HPLC/UV method. However. it was difficult to detect the saponins in Radix Astragali using a UV detector due to the lack of chromophore groups. The analysis of trace amounts was achieved by LC-ESI-MS/MS on account of its low detection limit and high specificity. In addition, the method showed good linearity, limit of detection, accuracy and precision. Oyerall. these simple. rapid, sensitive. reliable HPLC/UV and LC-ESI-MS/MS methods are suitable for the routine quantitative analysis and quality control of Radix Astragali.

Acknowledgment. This research was supported by a grant (06082KFDA224) from Korea Food \& Drug Administration in 2006.

\section{References}

1. Benshy: D: Gamble. A. Chinese Herbal Medicine: Maleria Medica. Revised Ed.: Eastland Press: Seattle. 1993.

2. Kajimura, K.: Takagi, Y; Ueba. N.: Yamasaki, K: Sakagami, Y: Yokoyama. H; Yoneda, K. Biol. Pham. Bull 1996. $19,855$.

3. Dong. T. T.: Ma. X. Q.: Clarke. C.: Song. Z. H.: Tí. Z. N.: Lo. C. K.: Tsim. K. W. J. Agric. Food Chent 2003. 51.6709.

4. Wang. X. J.: Feng. P. Acta Phamacol Sin. 2000.21. 1141.

5. Lee. Y. S.: Han, O. K.: Park, C. W.: Suh. S. I.: Shin, S. W.: Yang. C. H: Jeon, T. W.: Lee, E. S.; Kim. K. J; Kim. S. H.: Yoo. W. K; Kim. H. J. J. Ethopharmacol 2003. 84. 193.

6. Mills. S.: Bone. K. Principles and Practice of Phytotherapy: Editnburgh: Churchill Livingstone. Scotland. 2000). p 273.

7. Yoshida. Y: Wang. M. Q.: Litı. J. N. Int. J. Immmophomacol. $1997.19,359$

8. Ma. X. Q. Shi. Q.: Duan. J. A. J. Agric. Food Chem 2002, 50. 40.

9. Wu, T:: Bligh, S. W. A.: Gu. L.-h.; Wang, Z.-t.: Liu. H.-p.: Cheng. X.-m.: Brandtord-White. C. J.: Hu. Z.-b. Fitoterapia 2005. 76. 157.

10. Zheng. Z. R.: Song. C. Q.: Liu. T.: Hu. Z. B. Acta Pharn. Sin. 1998. 148.33

11. Xiao. H. B.: Krucker. M.: Albert. K.: Liang. X. M. J. Chromatogr A 2004, 1032. 117 .

12. Xiao, H. B.: Krucker. M.; Putzbach. K ; Alhert, K. J. Chromatogr: A 2005. 1067. 135.

13. Ministry of Public Health of the People's Republic of China: Phornacopeia of the People s Republic of China: 2005: Iol. 1. p 212.

14. Pan. F: Feng, Y. X.: Chen. S. B.: Gao. G. Y. China J. Chin. Materia lled. $1995,391,20$

15. Ganzer. M.: Bedir, E: Calis. 1.: Khan, 1. A. Chomatographia 2001.53. 131.

16. Li. W. K.: Fitcloff. I. F. J. Chomatogr: Sci. 2001. 39. 459

17. Yao. M. C.: Qi. Y.: Bi. K. S.: Wang. X.: Luo. X: Che. C. T. J. Chromatogr: Sci. 2005, 38. 325.

18. Gu. Y. C.: Wang. G. J.: Fawcett, J. P. J. Chronatog: B 2004 801. 285

19. Qi. L. W: Yu, Q. T; Li, P. Li. S. L.: Wang, Y. X; Sheng, L. H: Y1. L. J. Chromatogh A 2006. 113t. 162.

20. Liang. M.: Zhang. W.: Hu. T.: Liu. R.: Zhang. C. J. Pham Bioned Anal 2006. +2.178.

21. Han. S. B.; Jang, M. S.: Lee. H. J.: Lee. Y; Yu, C.: Lee. K. R: Kim. H. Bull Kowan Chem. Soc. 2005. 26.729.

22. Choi. Y. W.: Nam, D.: Kang. K. H; Ha. K. W. Han, I. H.: Chang. B. K.: Yoon. M.: Lee. J. Bull Korean Chem. Soc. 2006. 27. 291 